\title{
Diagnostic imaging pathways in the setting of acute chest wall trauma
}

\author{
Carlos Galvez ${ }^{1}$, Juan Arenas-Jimenez ${ }^{2}$, Jone Del Campo ${ }^{1}$, Sergio Maroto ${ }^{1}$, Marina Sirera ${ }^{2}$, Francisco Lirio ${ }^{1}$ \\ ${ }^{1}$ Department of Thoracic Surgery, ${ }^{2}$ Department of Radiology, Hospital General Universitario Alicante, Alicante, Spain \\ Contributions: (I) Conception and design: C Galvez, J Arenas-Jimenez; (II) Administrative support: All authors; (III) Provision of study materials \\ or patients: All authors; (IV) Collection and assembly of data: C Galvez, J Arenas-Jimenez; (V) Data analysis and interpretation: All authors; (VI) \\ Manuscript writing: All authors; (VII) Final approval of manuscript: All authors. \\ Correspondence to: Carlos Galvez, MD, PhD. C/Pintor Baeza, 12. 03010, Alicante, Spain. Email: carlos.galvez.cto@gmail.com.
}

\begin{abstract}
Recognition of thoracic injuries during trauma assessment must be a priority due to the potential severity of intrathoracic or intrabdominal lesions. While primary care is carried out following the Advanced Trauma Life Support (ATLS) protocols, special attention must be taken to detect life-threatening conditions such as tension pneumothorax, pericardial tamponade or massive hemothorax, guided by clinical suspicion, assessment of the trauma mechanism and noninvasive imaging techniques available in situ or in the emergency department. Chest X-ray and bedside ultrasound (focused assessment in sonography for trauma, FAST) are the initial tests for unstable patients, higher clinical suspicion or high-energy mechanism of accident. After initial resuscitation, during the secondary surgery, chest computed tomography (CT) is the cornerstone test for assessing the presence of intrathoracic lesions secondary to penetrating or highenergy trauma, that can potentially threaten patient's life. Concise and early detection can be life-saving and determines the final results. In this article we review these techniques and their indications.
\end{abstract}

Keywords: Thoracic injuries; diagnostic imaging; Advanced Trauma Life Support Care (ATLS Care)

Received: 02 October 2019; Accepted: 04 November 2019; Published: 05 April 2020.

doi: $10.21037 /$ jovs.2019.11.08

View this article at: http://dx.doi.org/10.21037/jovs.2019.11.08

\section{Introduction}

Thoracic trauma is one of the most common locations of injury (after head and extremities), and has an overall mortality rate of up to $10 \%$ (1), so recognition of intrathoracic injuries must be a priority in chest trauma assessment. Trauma is the fifth leading cause of death worldwide, and is the leading cause in people younger than 40 years old (2).

Patients with chest wall trauma are at significant risk for intrathoracic or intraabdominal injuries based upon their mechanism of injury or initial clinical assessment, thus, unless they require immediate surgery, these patients usually warrant further diagnostic imaging.

Either for life threatening conditions that require an emergent response, or for minor injuries, imaging is a key tool to guide many of the interventions and decisions in patients with chest trauma. Conventional tests like chest radiographs and ultrasound, and computed tomography (CT) are the imaging techniques usually performed in the emergency setting (3).

We should review traumatic thoracic injuries from a severity point of view. Despite borders among the clinical outcomes of different lesions are not always clearly defined, and some initially irrelevant lesions can turn into clinical severe conditions, we can divide traumatic thoracic lesions into three levels of priority and severity, and imaging tests should be used accordingly: life-threatening conditions, injuries associated to high energy trauma, and mild chest trauma.

Portable chest $\mathrm{X}$-ray (CXR) is usually the first imaging test to be performed in major trauma patients, since it can detect life-threatening injuries such as tension pneumothorax, massive hemothorax, and malposition of tubes or lines (4). Bedside thoracic ultrasound (focused 
Table 1 NEXUS chest criteria

Age $>60$ years
Rapid deceleration mechanism [fall $>6$ meters ( 20 feet) or
motorized vehicle accident $>65 \mathrm{~km}$ ( 40 miles) per hour]
Chest pain
Intoxication
Distracting injury
Tenderness to chest wall palpation
Abnormal alertness/mental status

NEXUS, National Emergency X-radiography Utilization Studies.

assessment in sonography for trauma, FAST) in experienced hands can aid to quickly guide management of some of these events, which cannot await until CT is performed. For high-energy trauma, CT is mandatory, since it depicts the whole range of traumatic chest lesions together with abdominal, neurological and spine injuries that frequently concur in these patients. For mild chest trauma, conventional upright posteroanterior and lateral chest radiographs together with oblique views detect many chest wall and associated pleural lesions. In these patients, chest ultrasound is a reliable technique (5) that can even detect more rib fractures than radiographs.

In this review article, we will describe the indications of these diagnostic techniques, when to use each technique, their role and limitations, and the main imaging findings of most important traumatic lesions.

\section{Primary survey: life-threatening conditions}

First step in a thoracic trauma setting is to identify lifethreatening conditions that might potentially lead to patient's death. The classic management protocol from Advanced Trauma Life Support (ATLS) (3) from the American College of Surgeons is vital to initiate resuscitation while detecting some of these challenging conditions. Clinical signs and symptoms are cornerstone, but in many cases, prompt diagnosing tests are essential for making the correct management decisions.

These imaging tests should be easily and quickly available in the prehospital setting or in the Emergency Department (ED), should be reliable, and must not delay decisionmaking process. Plain CXR (either portable or conventional posteroanterior) and ultrasound are mainly the initial tests to rule out the potentially fatal injuries.
Table 2 Clinical findings suggesting intrathoracic injury

Severe mechanism of injury

Hemodynamic instability

Significant tenderness

Seatbelt sign across abdomen

Hypoxia

Clinical signs of multiple rib fractures

The aim of these tests is to early detect tension pneumothorax, massive hemothorax, pericardiac tamponade, airway rupture and flail chest.

\section{CXR}

CXR is useful during the primary survey of thoracic trauma, either in the ED or in the operating room (OR), in order to detect life-threatening injuries that may be missed. It is inexpensive, noninvasive, and easy to obtain.

It should be performed in any patient with concerning chest wall trauma, and can be avoided in superficial soft tissues injuries where intrathoracic injuries are unlikely. A normal CXR in low-risk patients avoids the need for further studies.

The NEXUS (National Emergency X-radiography Utilization Studies) Chest decision instrument showed that severe intrathoracic injury is highly unlikely in the absence of all the criteria shown in Table 1, so if one is present, an initial simple test like CXR should be performed (6).

These criteria have proved high sensitivity $(98.8 \%)$ and negative predictive value $(98.5 \%)$ for detection of thoracic injury seen on chest imaging, but with low specificity $(13.3 \%)$, which means that many positive results are false positives (7).

In cases of penetrating trauma, if a chest CT is planned, there is usually no need for a routine plain CXR, but it is recommended even in stable patients, because it can show subdiaphragmatic air, foreign bodies/fragments, pneumoor hemothorax.

CXR is performed in blunt trauma of any significance, either if clinical findings suggest injury (Table 2) or in hemodynamically unstable patients, unless they require immediate chest CT or urgent surgery (8). In these highrisk patients, portable anteroposterior CXR might not have enough sensitivity to detect injury, so minor findings on CXR or clinical concern should be followed by advanced 


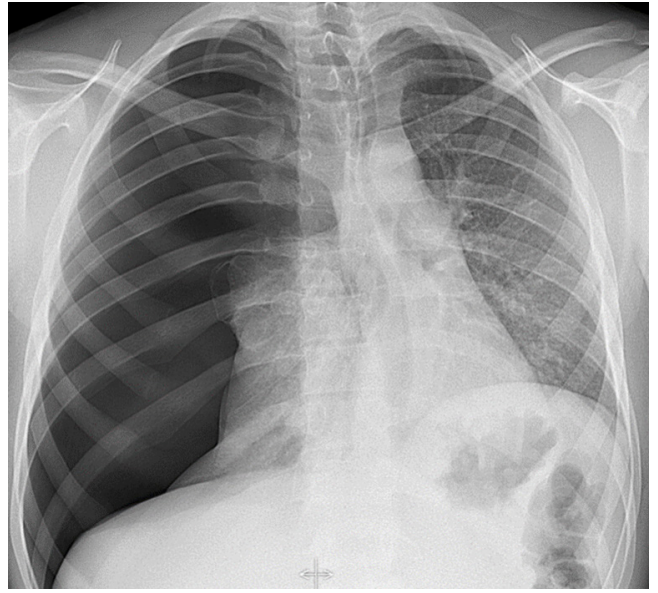

Figure 1 Tension pneumothorax. In chest X-ray, pneumothorax extends along the whole right hemithorax widening intercostal spaces, with a complete collapse of the right lung and displacing mediastinum to the left.

imaging tests like chest CT.

CXR in blunt trauma can evidence the presence of pneumothorax, hemothorax, pulmonary contusion, bone fractures and signs of blunt aortic injury (BAI). In spite of its proven clinical utility, it must be kept in mind that many of the injuries found on CT (mainly multi-detector CT), are missed on CXR, and 20\% of these lesions can influence decision-making (1).

\section{Findings}

Initial assessment with CXR aims to discover lifethreatening conditions such as tension pneumothorax, massive hemothorax, pericardial tamponade, severe flail chest or airway rupture.

* Tension pneumothorax: the "visceral pleura lineal sign" is the most common finding in traumatic pneumothorax, and reflects separation between both visceral and parietal pleural layers with air trapped inside (4). In absence of the characteristic pleural line, other radiological signs that help to diagnose pneumothorax in the supine position CXR are the "deep sulcus sign" finding a hyperlucent and deepened costophrenic sulcus, the "double diaphragm sign" due to basal air laying above the diaphragm, and a "unilateral hyperlucent lung" without an apparent visceral pleural line $(4,9,10)$ (Figure 1).

If not detected in an early stage, pneumothorax can evolve into tensional, that is a clinical diagnosis that usually manifests radiologically as contralateral mediastinal shift, diaphragm inversion and widening of intercostal spaces. This is a lifethreatening situation with risk of cardiac arrest and requires prompt pleural decompression with the available tools (3).

* Massive hemothorax: accumulation of blood in the pleural space can be life-threatening if massive or can evolve into pleural complications like fibrothorax or clotting with subsequent empyema. Opacification of the lower hemithorax or the costophrenic sulcus is the most common radiological finding in CXR (Figure 2), with massive hemothorax appearing as whole opacification of the hemithorax (4), and potential diaphragmatic inversion or mediastinal shift $(4,11)$. If concomitant with pneumothorax, an air-fluid level can be easily detected.

With the exception of small collections due to rib fractures, it's recommended to drain with a large caliber chest tube (24-28 Fr) and if necessary fluid and/or blood infusion. Some cases of high initial output (>1,500 cc) with hemodynamic instability, persistent high output (>200 cc 2-4 hours) or need for repeated blood transfusion, claim for urgent surgical review (3).

* Pericardial tamponade: although more common in penetrating trauma, injuries to the heart or pericardium may potentially produce cardiac tamponade due to accumulation of blood in the pericardial space, with the subsequent risk of cardiac arrest. Assessment of clinical signs such as arterial hypotension, paradoxical pulse and diminished heart sounds is of major importance, and CXR can give some suspicion signs.

Global enlargement of cardiac silhouette is the most common radiological finding (Figure 3). Other signs include the "water-bottle sign" and the "oreo cookie sign" (separation of epicardiac and pericardial fat by pericardial effusion) (1). Pneumopericardium or abnormal cardiac silhouette due to herniation of some part of the heart through pericardial tears are less frequent findings (4).

Urgent subxiphoid or parasternal pericardiocentesis, followed by surgical exploration are the indicated therapeutic options (3).

* Severe flail chest: flail chest is in fact a clinical 

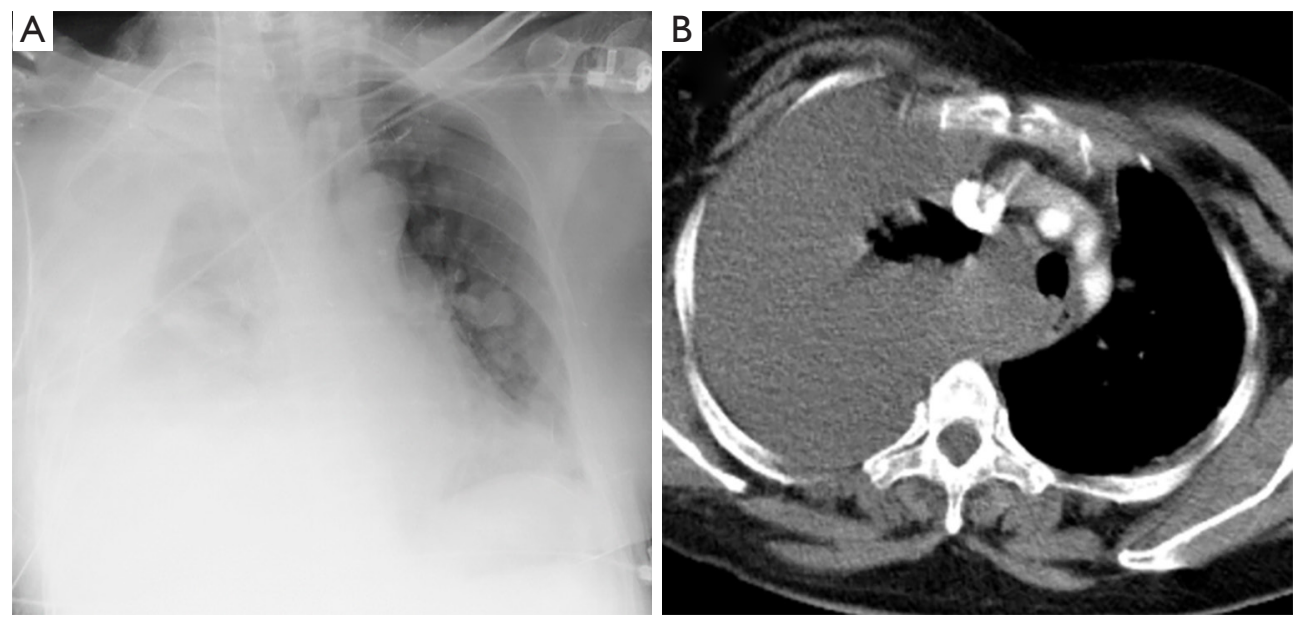

Figure 2 Massive hemothorax. (A) Chest X-ray shows right hemithorax opacification with left mediastinum displacement; (B) axial view in CT shows contralateral mediastinal displacement and ipsilateral lung compression. CT, computed tomography.
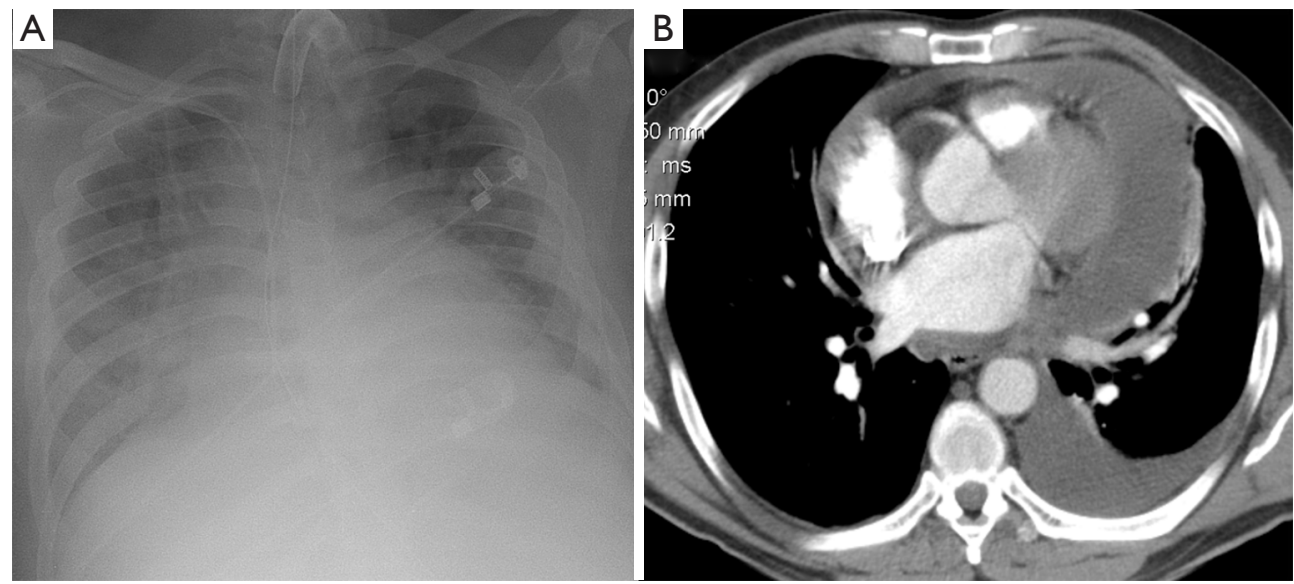

Figure 3 Pericardial tamponade. (A) chest X-ray shows significant enlargement of cardiac silhouette; (B) chest CT axial section shows blood in the pericardial space, mainly located in the lateral wall. CT, computed tomography.

diagnosis. Secondary to thoracic trauma, some ribs can break in two different locations, so when several ribs are affected, a segment of the chest wall exhibits paradoxical motion while breathing, collapsing during inspiration and protruding in expiration (1). When a significant segment of the chest wall is affected, patients can develop respiratory insufficiency, sometimes requiring orotracheal intubation and mechanical ventilation (12).

Evidence of three or more adjacent ribs broken in two different locations associated with clinical worsening should concern of a potential complication.
* Airway rupture: although not considered traditionally a life-threatening condition in the primary survey, tracheobronchial rupture might become an emergency and, in fact, the majority of airway ruptures are fatal prior to arrive to hospital (1). They should be suspected after highspeed deceleration or crush injuries, which can compress the airway against bone structures, tear from fixed structures or elevate internal pressure against a closed glottis.

Severe pneumomediastinum and/or subcutaneous emphysema, or persistent collapsed lung after chest tube placement in a pneumothorax are typical 

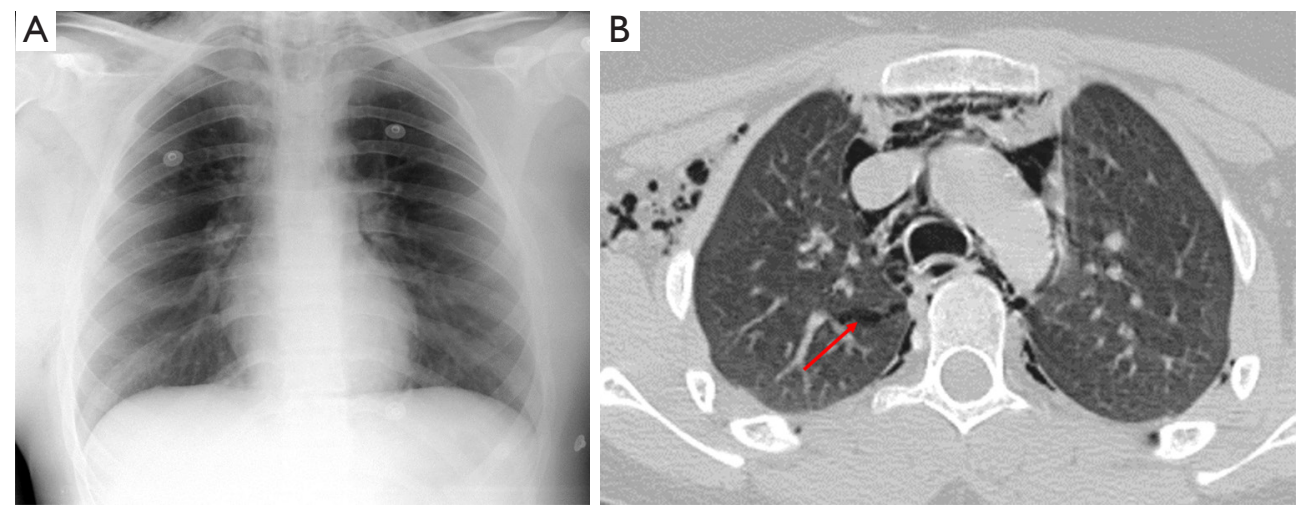

Figure 4 Airway rupture. (A) Chest X-ray showing subcutaneous emphysema at the neck base is readily apparent; mediastinal air in left is also seen; (B) traumatic pneumomediastinum without other significant lesions. Linear intrapulmonary air due to Macklin effect is shown in the right upper lobe (arrow). Subcutaneous and extrapleural air in the paravertebral and intercostal fat are also seen.

radiological signs, and must alert of the need for diagnostic and therapeutic fiberbronchoscopy and, in some cases, orotracheal intubation beyond the disrupted area (13) (Figure 4).

\section{Focused assessment with sonography for trauma (FAST)}

Identification of pathologic pericardial, intrathoracic or intraperitoneal free fluid as hypo or anechoic, or the presence of pneumothorax, are the main objectives of FAST $(14,15)$. It is only contraindicated in patients who need immediate surgery.

Ultrasonography has the potential advantage of decreasing initial evaluation time and exposure to ionizing radiation, it is easy to learn, noninvasive and inexpensive, and can be easily repeated while the patient remains in the ED thus allowing for continuous reassessment of the patient increasing its accuracy (16).

FAST is performed in unstable patients (primary survey) and stable patients with chest wall trauma (secondary survey), for identifying life-threatening conditions, mainly cardiac tamponade and intraperitoneal bleeding, as well as massive hemothorax and pneumothorax (extended-FAST).

As FAST is not performed by skilled ultrasonographers, in the ED setting, it plays just an initial screening role in the management of thoracic trauma, and does not avoid the need for further studies in stable patients (chest CT), but it has the potential to diagnose intraperitoneal bleeding that directly leads to abdominal surgery in severely unstable patient.

Ultrasonography has limited and heterogeneous sensitivity (42-100\%) (17), thus negative results in highsuspicion stable patients must carry the performance of further imaging tests or invasive maneuvers like pericardial window. It is more sensitive for injury in blunt trauma than in penetrating trauma, thus negative results in penetrating trauma must be taken with caution.

According to the guidelines of ATLS, the FAST exam is typically performed during the assessment of circulation and hemorrhage in the primary survey (3). A low frequency (2.5 to $5 \mathrm{MHz}$ ) curvilinear probe is used to allow for appropriate depth view.

Standard order of evaluation is as follows:

* Pericardial (rule out pericardial tamponade first);

* Right flank (hepatorenal view);

* Left flank (perisplenic view);

* Pelvic (retrovesical view);

- Thoracic (rule out pneumothorax and hemothorax).

Some conditions can difficult ultrasound assessment by FAST, such as subcutaneous emphysema or hyperinflated lungs from chronic pulmonary disease.

\section{Findings}

* Pericardial tamponade/hemopericardium: the first and main objective is to detect the presence of pericardial fluid (blood) between the two layers of pericardium, as an anechoic dark image. It can detect as little as 20 cc of fluid in the pericardial space (18) and also allows the operator to assess the presence of pericardial tamponade by evaluating wall motion or right ventricle filling abnormalities.

Epicardial fat pads can be distinguished because 


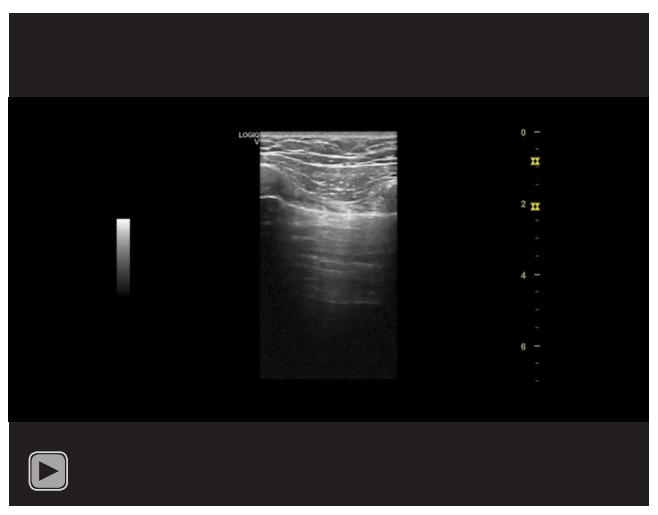

Video 1 The lack of pleural sliding between both the parietal and visceral layers in a patient with traumatic pneumothorax (27).

they move synchronous to heart wall motion, while pericardial bleeding remains independent (19). Most common window for cardiac review is the subcostal view, performed in the subxiphoid region. Alternatives are the parasternal long and the apical four chamber views. After an initial negative result in the setting of a high clinical suspicion, it's recommended to repeat again the pericardial examination once the hemothorax has been removed with a chest tube. The reason is that a pericardial tear can drain blood from the pericardial space into the pleura, and also the presence of blood in the pleural space limits pericardial assessment $(19,20)$.

Ultrasonography has showed $100 \%$ and $96.9 \%$ sensitivity and specificity respectively for the diagnosis of hemopericardium, and mean time to surgery of $12.1 \mathrm{~min}$ in a prospective study with 261 cases of penetrating thoracic trauma, 29 of whom had findings of hemopericardium (21). It can also improve survival compared to non-ultrasonography use (22), and decrease the need for pericardial sub-xiphoid windows to assess the presence of hemopericardium (23).

* Hemothorax: accumulation of blood in the pleural space appears as hypoechoic stripe in the FAST examination (as little as $20 \mathrm{cc}$ is potentially visualized) $(24,25)$, and it is usually located in the posterior costophrenic sulcus in the supine patient. It should alert on the possibility of intrathoracic injury and many times requires further imaging tests or procedures such as chest tube placement. Right and left flank views are typically used to rule out hemothorax. Ultrasonography has been shown to be more sensitive and specific for traumatic hemothorax when compared to CXR with nearly a $100 \%$ sensitivity and specificity for hemothorax, and almost none false positives in skilled operators $(25,26)$.

* Pneumothorax: pneumothorax is one of the most common serious injuries in the thorax, and one of the most frequent preventable causes of death in trauma, thus the importance of early diagnosis (16). The presence of air in the pleural space requires detailed visualization of the interface between both layers, with a high-frequency $(5-10 \mathrm{MHz})$ linear transducer probe. The third-fourth intercostal space midclavicular line is the most typical location for this purpose, but there is no determined best approach. Common findings for pneumothorax are lack of sliding of the pleural layers (Video 1) and lack of the comet tail sign (areas of interstitial edema in the visceral pleura). Presence of pleural sliding adjacent to areas of absence of this sign usually represent the edge of a pneumothorax. In cases of tension pneumothorax, no pleural sliding can be visualized in the affected hemithorax.

Multiple studies suggest ultrasonography is more sensitive than supine CXR for diagnosing pneumothorax (28-31), using chest CT as the gold standard. A 2012 meta-analysis showed a $90.9 \%$ sensitivity, $98.2 \%$ specificity, and $94.4 \%$ and $97 \%$ of positive and negative predictive values respectively (32).

What is not still determined is the need for further treatment in cases of small pneumothoraces found during e-FAST examination, as it happens in chest CT (16).

\section{Secondary survey: high-energy trauma}

Once life-threatening injuries have been discarded and the patient is stabilized, most patients with high-energy trauma are evaluated with CT. CT is the technique of choice since it can confidently detect and depict most traumatic lesions and permits an integrated evaluation of accompanying abdominal and skeletal lesions.

Although for a review purpose an anatomical division of the possible injuries is usually followed, lesions in multiple anatomical spaces are more frequent, and due to the unique characteristic of the lung as an air-filled viscus, for each anatomic location air and fluid/hematic collections of variable importance can be found.

It is not well determined yet if routine thoracoabdominal CT or if only selective CT should be performed in blunt 

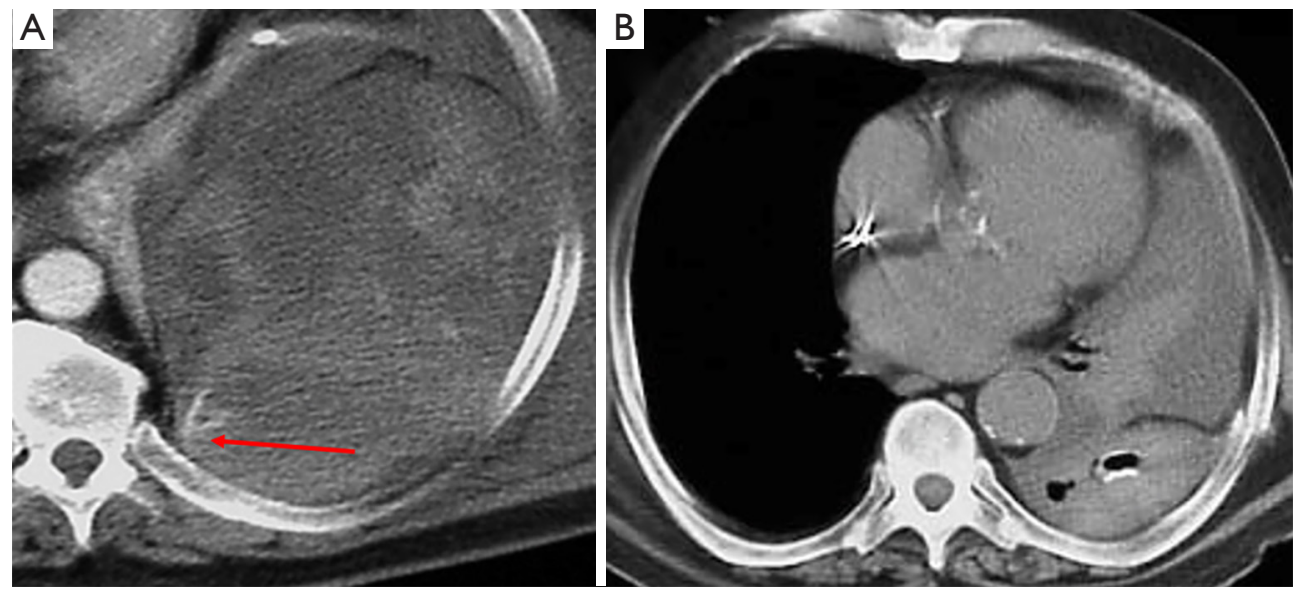

Figure 5 Extrapleural hematoma. High attenuation collections in the extrapleural space are separated from the pleural effusion by a fat attenuation stripe. In (A) active bleeding from an intercostal artery is seen (arrow); in (B) the chest tube is inserted in the extrapleural space.

high-energy trauma (2).

\section{Chest wall}

Depending on whether it has been a penetrating injury or not, and on the mechanism of trauma, lesions of the chest wall are varied.

Some grade of air collections is frequent in the chest wall fat, usually around muscular structures however, massive subcutaneous emphysema requiring direct intervention is rare. For blunt chest trauma, the presence of subcutaneous air should prompt further diagnostic search for pleural or mediastinal air as the origin.

Chest wall hematomas are almost always associated to rib fractures, and usually small or middle sized. When big, they are usually associated to anticoagulation or a vessel injury, mostly the intercostal arteries. In those cases, careful evaluation by means of CT angiography and if necessary delayed images to demonstrate active bleeding can help the interventional radiologist to guide an embolization (33). A specific type of chest wall hematoma is extrapleural hematoma that occurs when blood proceeding from the chest wall extends inside the thoracic cavity but does not traverse the intact parietal pleura. Extrapleural hematomas are limited by the endothoracic fascia, and characterized by the inward displacement of the extrapleural fat stripe (Figure 5). They are frequently associated to rib fractures and when show a biconvex shape, usually require surgical drainage (34).

Rib fractures are a marker of severity in chest trauma, although their presence depends on the mechanism, strength and previous condition of the bone. Pain and potential flail chest are the main clinical consequences of rib fractures. Rib fracture fragments can transform blunt trauma into penetrating trauma (1) (Figure 6). In a large series (35) there was a significant association between the mortality rate and number of rib fractures, the patient's age and injury severity score, and the number of rib fractures was significantly related with the presence of hemothorax or pneumothorax.

Even with dedicated projections, radiography can miss rib fractures and both the use of sonography and CT detect more fractures (Video 2). CT is the preferred diagnostic imaging test for rib fractures, and it can evidence mainly two types: buckling of the cortex (which are often missed in conventional CXR) and actual fracture gap (Figure 6B). However, missed rib fractures are not uncommon, specially buckle fractures, which are frequently overlooked (37). Dedicated software that permits unfolded reconstructions of the rib can aid to detect fractures in polytraumatized patients in a shorter time (38). Although it isn't better for detecting fractures (39), 3D evaluation can better depict relationship of fracture fragments and guide surgical management if necessary. Recently, application of preoperative $3 \mathrm{D}$ printing before surgical stabilization has been shown to be useful for shortening operation time and to get a smaller incision length (40), although its use is not yet still well defined. Rib fracture evaluation should include the injured levels, number, alignment, inward displacement and the presence of segmental fractures with at least two separate complete fractures in the same rib, since all these factors can be associated to an increased risk of complications and consequently require a more aggressive 

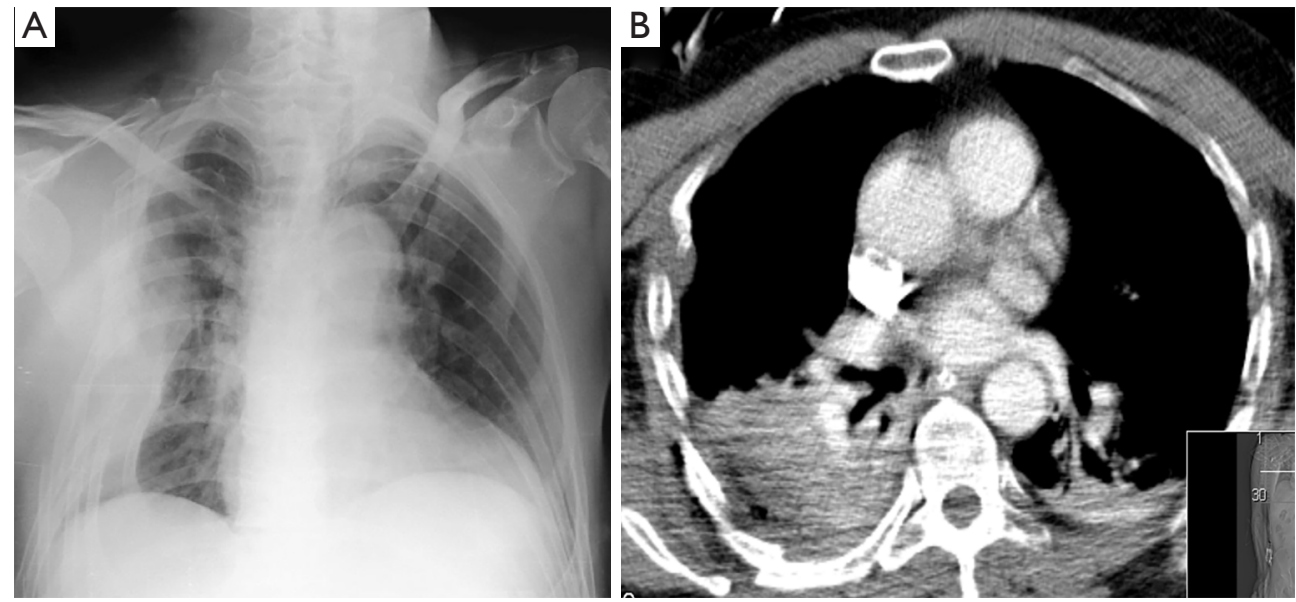

Figure 6 Rib fractures. (A) A severe thoracic trauma with multiple ribs broken in the right side producing a thoracoplasty with remodeling of chest wall shape; (B) axial CT with multiple ribs broken and some of them have torn the underlying lung parenchyma. CT, computed tomography.

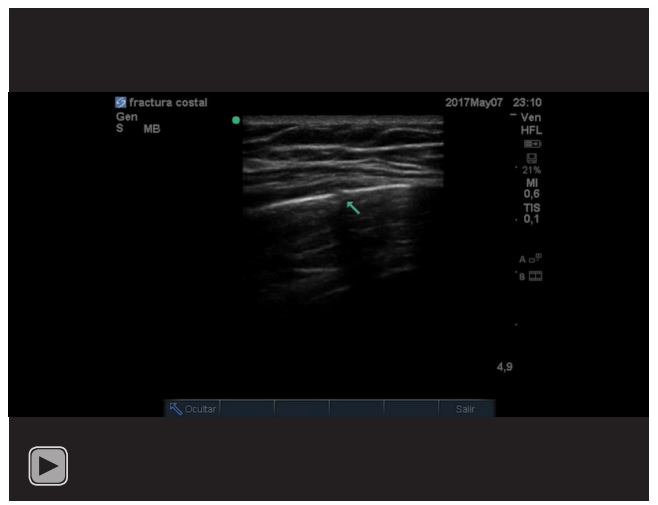

Video 2 An extended FAST examination that diagnoses the presence of rib fracture (36). FAST, focused assessment in sonography for trauma.

management (41).

The upper ribs fractures (usually the first through third/fourth ribs) require high-energy trauma and may be associated with vascular or brachial plexus injury $(9,10,42)$. First rib fractures are a marker of life-threatening injuries in major trauma, although in a study they do not independently increase mortality (42). Fractures below the eighth rib are significantly associated to intra-abdominal injury (43).

Sternal fractures are usually indicative of high-energy mechanism, mainly in traffic accidents, and almost all cases are associated with some grade of anterior mediastinal hematoma. Blunt cardiac injuries, specially right ventricle, should be ruled out and are more frequent in displaced
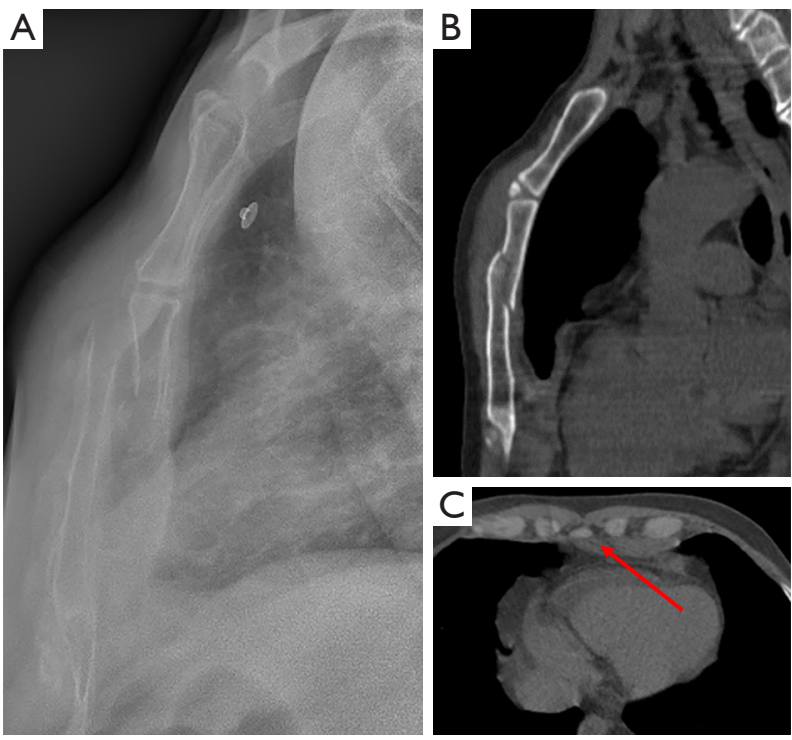

Figure 7 Displaced fracture of the body of the sternum accompanied by a small hematoma. (A) Lateral sternal radiography; (B) sagittal view in CT; (C) axial view in CT with underlying mediastinal hematoma (arrow). CT, computed tomography.

fractures (44), with cervical spine injuries, multiple chest rib fractures and pulmonary contusions being frequent concomitant lesions (45). Location of the fracture in the manubrium is also an indicator of severity (46). Lateral projection CXR but especially multiplanar reconstructions on CT are essential for diagnosis (1) (Figure 7). 


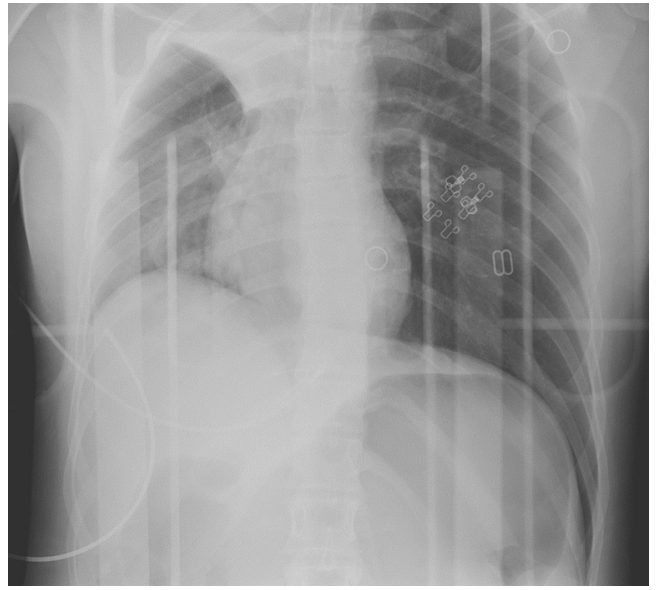

Figure 8 Portable decubitus chest X-ray shows the "deep sulcus sign" pointing to a big sized pneumothorax.

Scapular fractures are injuries associated to very highenergy mechanism usually appearing inferior to glenoid, and from lateral to medial. They can be easily missed in conventional CXR, and are commonly associated with other thoracic or upper extremities injuries. CT with threedimensional reconstructions is valuable for diagnosis and planning treatment $(1,10)$.

\section{Pleural injuries}

Hemothorax, pneumothorax or combined lesions are frequent in significant chest trauma. There have already been described the life-threatening conditions, but less important collections can be found associated to either parenchymal, mediastinal or chest wall injuries, in most instances with rib fractures.

Relative large amounts of either blood or air can be missed by decubitus chest radiographies. In a series, 55\% of pneumothoraces diagnosed on thoracic CT were missed by conventional supine radiographies, with subcutaneous emphysema, pulmonary contusion, rib fractures, and female sex as independent predictors of these occult pneumothoraces (47).

Findings suggesting pneumothorax on supine radiographs have already been mentioned above and are an increased lucency of the lung base, the "double diaphragm", excessive definition of mediastinal contour and perhaps the most reproducible "deep sulcus" sign (Figure 8). CT can also aid in the identification of the mechanism of the pneumothorax: an "outside-inside mechanism", where rib fracture fragments tear parietal pleura, or the "inside-outside mechanism" where a sudden increase in the intrathoracic pressure can produce alveolar rupture (1).

CT measurement of Hounsfield units (HU) may distinguish between conventional pleural fluid (less than $15 \mathrm{HU}$ ) or probable blood that usually has an attenuation of 35-70 HU, reaching higher levels when clotting appears $(1,9)$ (Figure 2B).

Apart from delimiting their cause, CT usually aids in the quantification and distribution of the collections and guides in their management. It must be kept in mind that mediastinal and abdominal lesions can be the origin of a pleural hematic collection. In large hemothorax, CT angiography can occasionally detect both the presence of active bleeding and the source, to potentially guide the interventional radiologist for embolization or the surgeon to proceed into an operation.

\section{Pulmonary injuries}

Pulmonary injuries can be mainly divided into those with alveolar disruption (laceration) or not (contusion) (1).

Pulmonary contusion is the most frequent lung damage after thoracic trauma, specially in blunt trauma. CT evidences pulmonary contusion at an early stage, as patchy airspace consolidation which do not follow pulmonary segmentation, and can be focal or multifocal, uni- or bilateral, or even diffuse (Figure 9).

Pulmonary lacerations are seen in penetrating trauma and high-energy blunt trauma, and usually coexist with contusion. They produce traumatic cavities in the lung (pneumatoceles, hematoceles or hemopneumatoceles) secondary to elastic recoil of lung tissue (Figure 10). They take weeks to months to completely recover and radiologically disappear, and if they affect the visceral pleura, a secondary traumatic pneumothorax can be seen. The most typical radiological appearance is a cavity filled with air and blood, but it can show only one of them. They can be classified into four types according to Wagner et al. (48):

* Type 1: compression rupture of central areas secondary to sudden and acute compression of the lung, occurring specially in young patients with flexible thorax;

* Type 2: compression shear, usually of the lower lobes resulting in a shearing injury across the spine, in the paravertebral areas;

* Type 3: rib penetration with laceration secondary to fractured rib which tears the lung surface, 

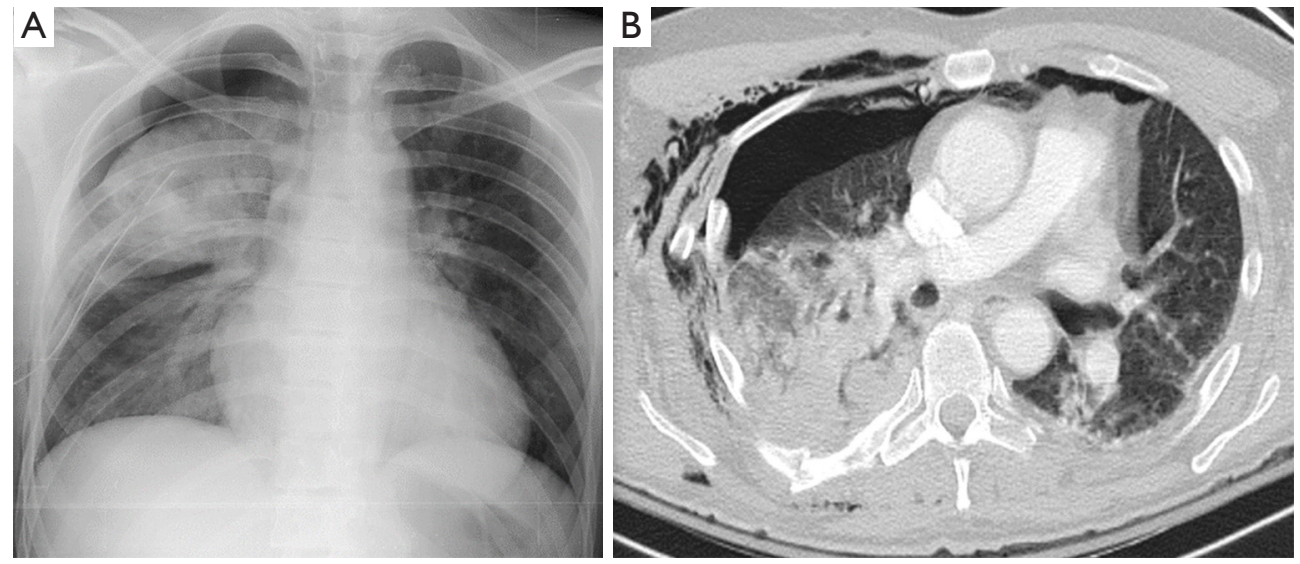

Figure 9 Pulmonary contusion. (A) Chest X-ray shows consolidation in the right upper lobe; (B) axial CT shows consolidation in the right upper lobe together with several displaced rib fractures, right pneumothorax, pneumomediastinum and subcutaneous emphysema. CT, computed tomography.

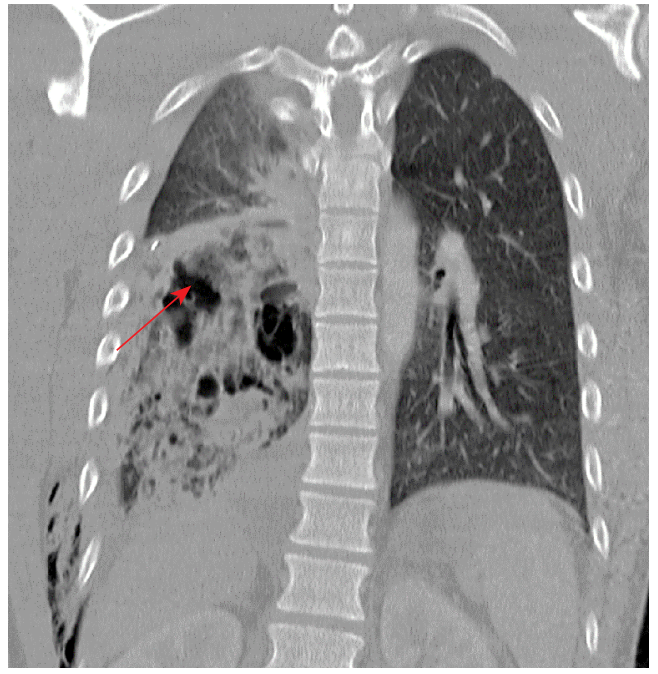

Figure 10 Pulmonary laceration. Consolidation and ground-glass opacities surround air cystic lesions corresponding to the lacerated lung. Arrow indicates pulmonary contusion.

usually associated with variable size of ipsilateral pneumothorax;

* Type 4: adhesion tears secondary to previous pleuropulmonary adhesions; difficult to diagnose, require review of past history and imaging.

\section{Airway}

Airway injuries are frequently seen after high-deceleration or crushing mechanisms of trauma, and usually become fatal before arriving to hospital. Disruption of airway wall is secondary to compression against bone, sudden elevation of intraluminal pressure against closed glottis, or shear in fixation points (9). These lesions are more common in the bronchi, within the 2 first centimeters from carina, and can be transverse or longitudinal.

CT can identify the exact disruption of the wall (between cartilages or in the junction between cartilage and membranous wall). An indirect sign of bronchial disruption is the "fallen lung" sign, where a lung remains collapsed in the lower portion of the cavity even though a chest tube has been inserted $(4,10)$ (Figure 11).

Although pneumomediastinum can occur in blunt trauma due to tracheobronchial and esophageal injuries, air usually originate from lung parenchymal injury. If the cause is not readily apparent, in a proportion of patients it is attributed to the Macklin effect that causes alveolar ruptures and air dissection along bronchovascular bundles. It is visualized as streaks of air surrounding and paralleling the bronchovascular bundles associated with pneumomediastinum (49) (Figure 4B).

\section{Esophagus}

Thoracic esophagus is rarely affected by thoracic trauma, because its central location and protection by surrounding structures (9). High-level falls are the main mechanism, and it's difficult to exactly locate the esophageal site on injury, and common indirect signs visualized are hydropneumothorax or pneumomediastinum. 

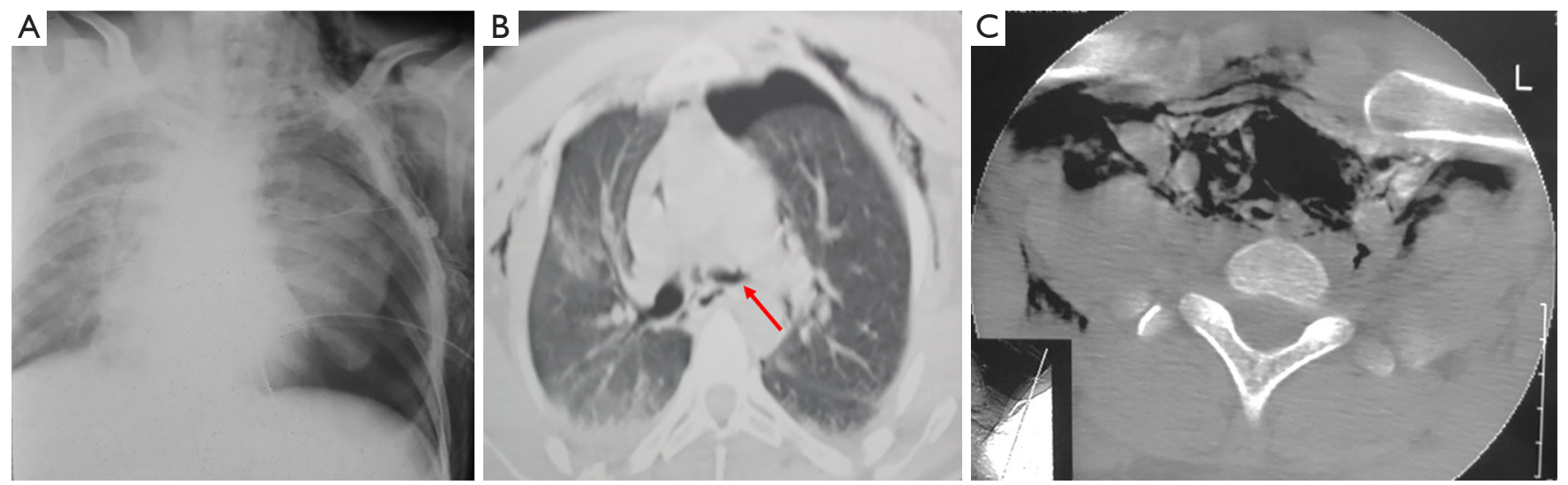

Figure 11 Airway rupture. (A) Persistent pneumothorax after chest tube drainage, collapsed lung and big sized subcutaneous emphysema in plain chest X-ray; (B) left main bronchus is disrupted showing irregularities (arrow) in its wall and lumen in axial CT; (C) tracheal rupture showed by absence of the trachea in this axial section of the CT due to a complete transection with distraction of its borders. CT, computed tomography.

\section{Heart and pericardium}

Heart injuries can be fatal if severe, but low-degree of severity lesions can often be seen. Typical mechanisms of cardiac injury are direct impact, rapid deceleration or compression between the sternum and the spine. The preferred term for traumatic cardiac lesions is blunt cardiac injury that encompass all the spectrum of lesions. In patients at risk, a combination of electrocardiogram, troponin, and echocardiography is mandatory for an adequate diagnosis, risk stratification and management (50).

Hemopericardium and pulmonary edema are the most typical findings in CT (1) (Figure 3B). Direct extravasation of contrast to pericardium or mediastinum can sometimes be seen if chamber perforation.

Pericardium can also be damaged in blunt or penetrating trauma, and usually appears as hemo- or pneumopericardium. Partial heart herniation through pericardial defects can be seen in CT.

\section{Diaphragm}

Traumatic injuries of the diaphragm occur after penetrating (gunshot, stab wounds) but especially after blunt trauma (51) (deceleration, high-falls, crushing in the thoracoabdominal region), and many times remain undiagnosed for an indeterminate period, so its real incidence can be higher. Left side lesions are more commonly seen, probably secondary to the protecting effect of the liver in the right side $(52,53)$.
In acute setting, consequences are directly related to associated injuries. In misdiagnosed cases, the pressure gradient between the abdomen and the thorax makes the diaphragmatic hernia increase in size during time, and a progressive herniation of abdominal organs into the thorax occurs (54). Acute, latent and obstructive are the common phases described by Grimes (55), with up to $85 \%$ of cases strangulated within 3 years of the original trauma (56).

Initial diagnostic test is CXR, where typical radiological findings (irregularity of diaphragmatic shape, elevation, mediastinal shift without other causes, and lower lobes atelectasis) in combination to clinical suspicion can be diagnostic enough. CT is the second-choice imaging test, with sensitivity and specificity up to $54-73 \%$ and $86-90 \%$ respectively $(51,57,58)$ with state of the art multidetector CT scans being superior to conventional CT (57) due to their multiplanar reformation capabilities. Its main limitations are when thick slices are used $(8-10 \mathrm{~mm})$, limitations for delineating the diaphragm from adjacent soft-tissues due to small amount of fat that permits its visualization and respiratory motion $(57,58)$ (Figure 12). CT can directly show the diaphragmatic defect itself, or indirectly show its existence as a stricture around the herniated viscus (the "collar or necklace sign") or by demonstrating a direct contact of the herniated viscera and the posterior chest wall (the "dependent viscera sign").

\section{Aortic blunt injury}

Traumatic aortic injury due to blunt chest trauma usually 

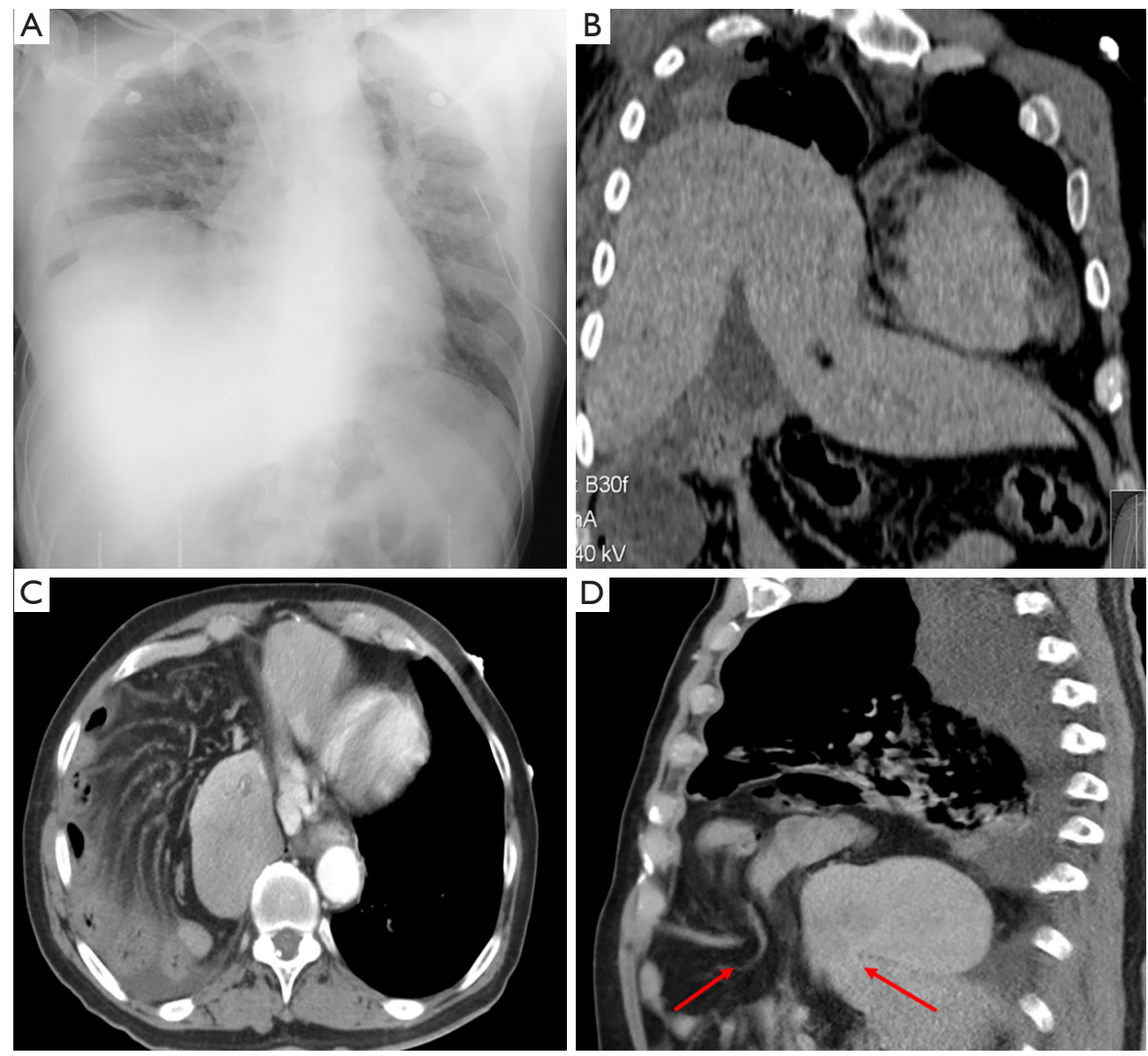

Figure 12 Traumatic diaphragmatic rupture. (A) Chest X-ray shows elevation of the right diaphragm with a hump corresponding to the herniated liver; (B) in the same patient as (A), CT performed 1 day later shows the liver in the right hemithorax; (C,D) axial and sagittal reformation in the same patient show a diaphragmatic defect [arrows in (D)] through which liver, mesentery fat and small bowel herniate. In both images the "dependent viscera sign" is seen with the viscera reaching the posterior pleural surface without the normal intervening diaphragm. In (D) the "collar sign" with a waist-like compression of the herniated structures at the level diaphragm defect (arrows) is seen. CT, computed tomography.

occurs as the result of motor vehicle collisions (59) and is an important cause of death at the accident scene. Aortic injury ranges from minimal intimal injury to complete aortic wall disruption and blood extravasation. The most common site of injury is the isthmus.

It should be suspected whenever a mediastinal hematoma next to the aorta is found on CT. An adequate thoracic CT angiography in a multidetector CT is the technique of choice for diagnosis, since it permits an adequate evaluation of the aortic lumen and the periaortic tissues.

It is beyond of the scope of this review the discussion on the management of traumatic aortic injuries, but it is clear that the diagnosis of minimal and contained ruptures is increasing due to the advances of imaging techniques (60) and that conservative and endovascular management are being recommended over the surgery in most instances $(61,62)$.

\section{Mild chest trauma}

Soft tissue trauma and rib fractures are the most frequent lesions associated to mild chest traumas, that are frequently due to falls, mainly in the elderly population (63). As aforementioned, despite mild trauma is usually uncomplicated, it can be a threatening condition in older patients with comorbidities, since in that population rib fractures are associated to an increased mortality due to 

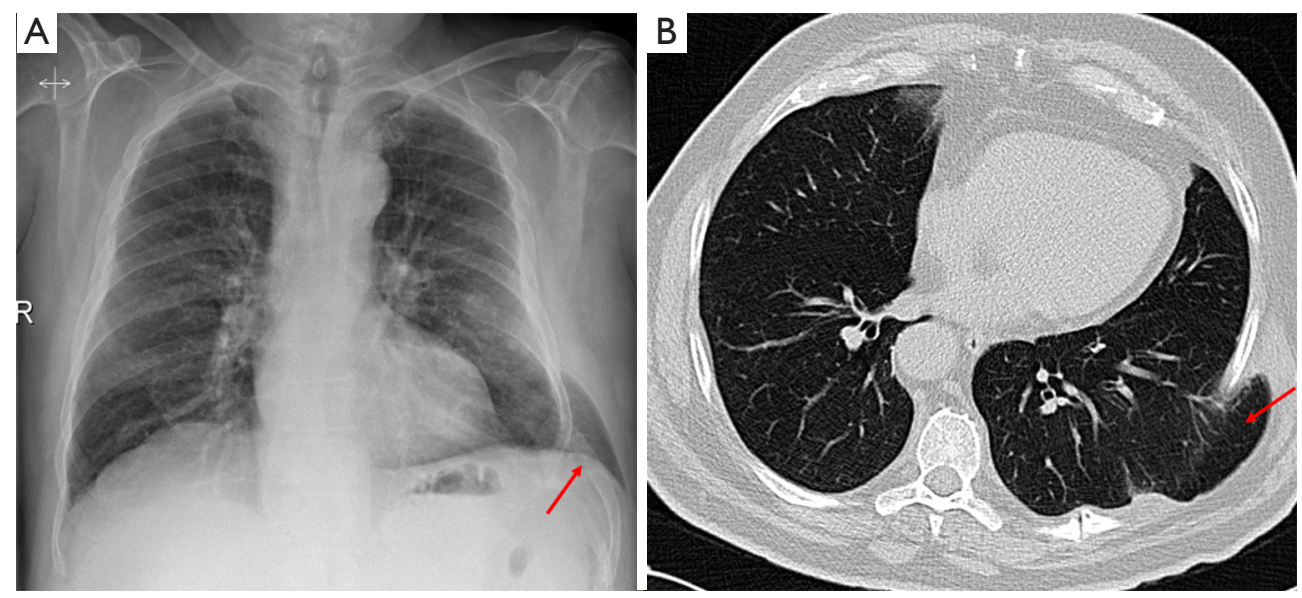

Figure 13 Traumatic pulmonary hernia developing after blunt chest trauma. Lung herniation though the intercostal space and a fractures callus are seen both in the chest X-ray and CT. (A) Posteroanterior chest X-ray with left pulmonary herniation (arrow); (B) axial view in CT of pulmonary herniation through intercostal disrupture (arrow). CT, computed tomography.

pulmonary complications $(63,64)$.

Low-risk stable patients can be ordered conventional posteroanterior and lateral CXR, and if they don't show any relevant findings, further tests can be avoided. Oblique views can help to detect more fractures, and dedicated ultrasound can detect even more rib fractures than radiographic techniques (65) but although they can give more details, they usually don't alter therapeutic management.

It must be kept in mind that even in mild trauma, pneumothorax and hemothorax can occur, that lower ribs fractures can be associated to significant abdominal lesions (66) and that the number of fractures increases the risk of complication (35). Patients under anticoagulation therapy should be managed with caution for the risk of clinically important hemorrhagic complications.

Other bone lesions such as sternal fractures can occur in mild direct trauma, specially in old patients and, if isolated, it carries a good prognosis $(67,68)$.

Sometimes mild traumas and persistent cough in emphysematous patients with weakened chest wall muscles present with pulmonary herniation through intercostal muscles. It can appear in combination to rib fractures, but might also appear isolated as a consequence of intercostal muscles disruption (Figure 13). These herniations are commonly undiagnosed initially, increase in size with time and the patients are referred for chest wall lumps with cough. CXR shows herniation of lung parenchyma through the intercostal space, and CT gives more detailed information about the exact site and size (69).

\section{Conclusions}

Thoracic trauma is a severe disease that must be addressed within trauma protocols, where clinical suspicion is essential for early diagnosis of potentially fatal injuries. Imaging tests are useful and reliable for classifying injuries in life-threatening conditions, injuries associated to high energy trauma and mild chest trauma. CXR and bedside ultrasound (FAST and e-FAST exams) are available, quick and non-invasive tests for early diagnosing lifethreatening conditions such as tension pneumothorax, massive hemothorax or pericardial tamponade that claim for urgent actions or immediate surgery. Chest CT scan is mandatory in high-energy trauma where intrathoracic or intrabdominal secondary lesions can be expected. It also gives additional information for late management of injuries. Concise and prompt performance of these tests can be life-saving and determines the final outcomes. Flowchart (Figure 14) summarizes the different imaging tests and their indications. 


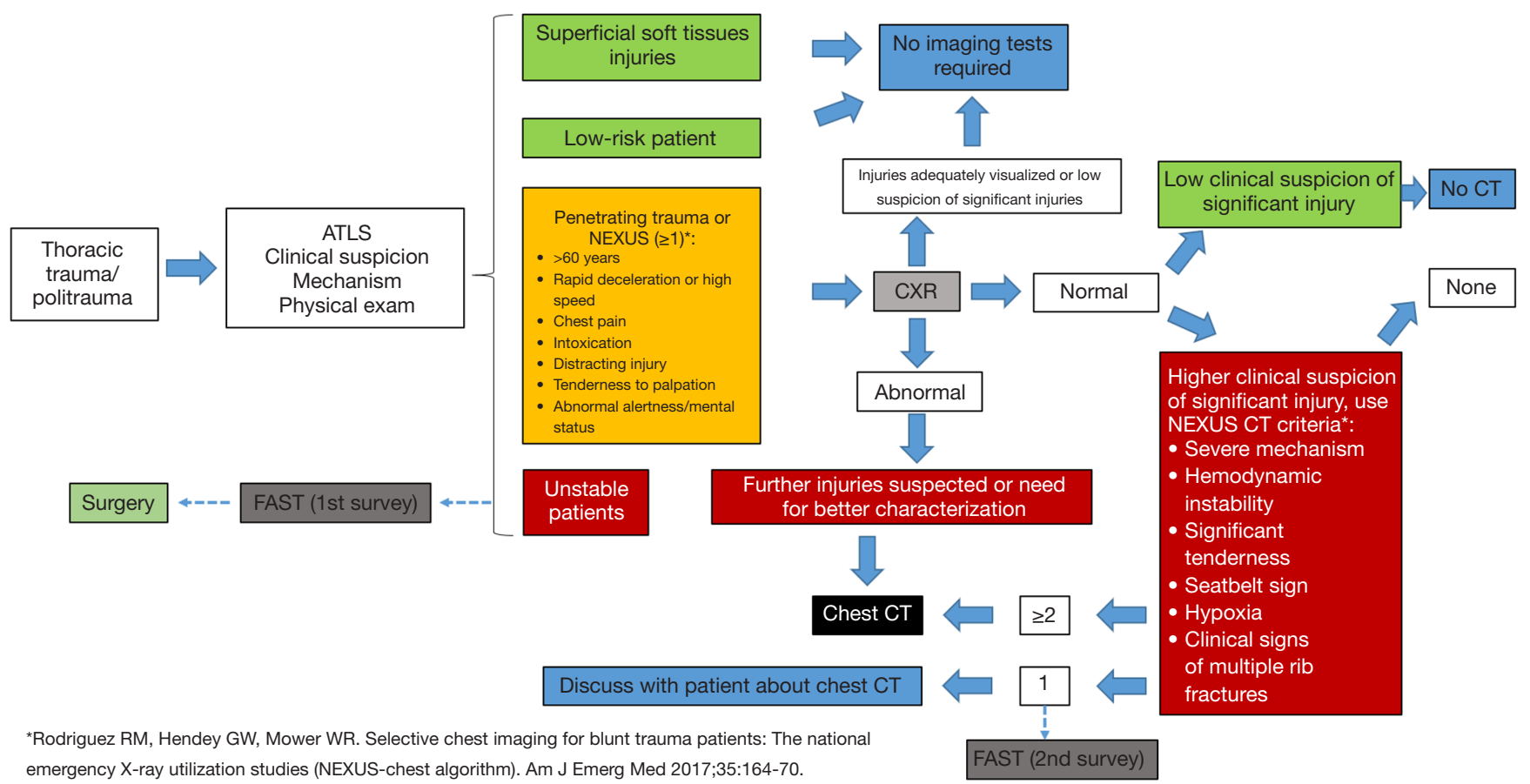

Figure 14 Diagnostic management of thoracic trauma. ATLS, Advanced Trauma Life Support; NEXUS, National Emergency X-radiography Utilization Studies; CXR, chest X-ray; CT, computed tomography; FAST, focused assessment in sonography for trauma.

\section{Acknowledgments}

To all the patients that could not be saved, those where something better could be done, those who shed the light for improvement changes.

Funding: None.

\section{Footnote}

Provenance and Peer Review: This article was commissioned by the Guest Editors (Marco Scarci and Fabrizio Minervini) for the series "Chest Wall Traumas" published in Fournal of Visualized Surgery. The article has undergone external peer review.

Conflicts of Interest: All authors have completed the ICMJE uniform disclosure form (available at https://jovs.amegroups. com/article/view/10.21037/jovs.2019.11.08/coif). The series "Chest Wall Traumas" was commissioned by the editorial office without any funding or sponsorship. The authors have no other conflicts of interest to declare.

Ethical Statement: The authors are accountable for all aspects of the work in ensuring that questions related to the accuracy or integrity of any part of the work are appropriately investigated and resolved.

Open Access Statement: This is an Open Access article distributed in accordance with the Creative Commons Attribution-NonCommercial-NoDerivs 4.0 International License (CC BY-NC-ND 4.0), which permits the noncommercial replication and distribution of the article with the strict proviso that no changes or edits are made and the original work is properly cited (including links to both the formal publication through the relevant DOI and the license). See: https://creativecommons.org/licenses/by-nc-nd/4.0/.

\section{References}

1. Sridhar S, Raptis C, Bhalla S, et al. Imaging of Blunt Thoracic Trauma. Semin Roentgenol 2016;51:203-14.

2. Van Vugt R, Keus F, Kool D, et al. Selective computed tomography (CT) versus routine thoracoabdominal CT for high-energy blunt-trauma patients. Cochrane Database Syst Rev 2013;(12):CD009743.

3. American College of Surgeons. Advanced Trauma Life Support. 9th edition. ATLS Student Course Manual. 2012. 
4. Ho ML, Gutierrez FR. Chest radiography in thoracic polytrauma. AJR Am J Roentgenol 2009;192:599-612.

5. Battle C, Hayward S, Eggert S, et al. Comparison of the use of lung ultrasound and chest radiography in the diagnosis of rib fractures: a systematic review. Emerg Med J 2019;36:185-90.

6. Rodriguez RM, Hendey GW, Mower WR. Selective chest imaging for blunt trauma patients: The national emergency X-ray utilization studies (NEXUS-chest algorithm). Am J Emerg Med 2017;35:164-70.

7. Rodriguez RM, Anglin D, Langdorf MI, et al. Validation of a decision instrument for selective chest imaging in blunt trauma. JAMA Surg 2013;148:940-6.

8. Holmes JF, Ngyuen H, Jacoby RC, et al. Do all patients with left costal margin injuries require radiographic evaluation for intraabdominal injury? Ann Emerg Med 2005;46:232-6.

9. Kaewlai R, Avery LL, Asrani A V, et al. Multidetector CT of blunt thoracic trauma. Radiographics 2008;28:1555-70.

10. Oikonomou A, Prassopoulos P. CT imaging of blunt chest trauma. Insights Imaging 2011;2:281-95.

11. Smith JA, Albarghuthy B, Khosla R. Inversion of the Hemidiaphragm due to Pleural effusion. Ann Am Thorac Soc 2014;11:1023-6.

12. Dehghan N, De Mestral C, Mc Kee M, et al. Flail chest injuries: a review of outcomes and treatment practices from the National Trauma Data Bank. J Trauma Acute Care Surg 2014;76:462-8.

13. Sangster GP, González-Beicos A, Carbo AI, et al. Blunt traumatic injuries of the lung parenchyma, pleura, thoracic wall, and intrathoracic airways: Multidetector computer tomography imaging findings. Emerg Radiol 2007;14:297-310.

14. American College of Emergency Physicians. Emergency ultrasound imaging criteria compendium. American College of Emergency Physicians. Ann Emerg Med 2006;48:487-510.

15. Lagi A, Marini F. Focused assessment with sonography for trauma. Sarti A, Lorini FL. editors. Echocardiography for Intensivists. 1st edition. Springer-Verlag Mailand, 2012:397-9.

16. Montoya J, Stawicki SP, Evans DC, et al. From FAST to E-FAST: an overview of the evolution of ultrasoundbased traumatic injury assessment. Eur J Trauma Emerg Surg 2016;42:119-26.

17. Miller M, Pasquale $M$, Bromberg W, et al. Not so FAST. J Trauma 2003;54:52-9. Discussion 59-60.
18. Governatori NJ, Saul T, Siadecki SD, et al. Ultrasound in the evaluation of penetrating thoraco-abdominal trauma: a review of the literature. Med Ultrason 2015;17:528-34.

19. Nicol AJ, Navsaria PH, Beningfield S, et al. Screening for occult penetrating cardiac injuries. Ann Surg 2015;261:573-8.

20. Ball CG, Williams BH, Wyrzykowski AD, et al. A caveat to the performance of pericardial ultrasound in patients with penetrating cardiac wounds. J Trauma 2009;67:1123-4.

21. Rozycky G, Feliciano DV, Ochsner M, et al. The role of ultrasound in patients with possible penetrating cardiac wounds: a prospective multicenter study. J Trauma 1999;46:543-51.

22. Plummer D, Brunette D, Asinger R, et al. Emergency department echocardiography improves outcome in penetrating cardiac injury. Ann Emerg Med 1992;21:709-12.

23. Nagy K, Lohmann C, Kim D, et al. Role of echocardiography in the diagnosis of occult penetrating cardiac injury. J Trauma 1995;38:859-62.

24. Röthlin M, Näf R, Amgwerd M, et al. Ultrasound in blunt abdominal and thoracic trauma. J Trauma 1993;34:488-95.

25. Ma O, Mateer J. Trauma ultrasound examination versus chest radiography in the detection of hemothorax. Ann Emerg Med 1997;29:312-5.

26. Brooks A, Davies B, Smethhurst M, et al. Emergency ultrasound in the acute assessment of haemothorax. Emerg Med J 2004;21:44-6.

27. Galvez C, Arenas-Jimenez J, Del Campo J, et al. The lack of pleural sliding between both the parietal and visceral layers in a patient with traumatic pneumothorax. Asvide 2020;7:035. Available online: http://www.asvide.com/ watch/33075

28. Rowan KR, Kirkpatrick AW, Liu D, et al. Traumatic pneumothorax detection with thoracic US: Correlation with chest radiography and CT - Initial experience. Radiology 2002;225:210-4.

29. Kirkpatrick AW, Sirois M, Laupland KB, et al. Handheld thoracic sonography for detecting post-traumatic pneumothoraces: the Extended Focused Assessment with Sonography for Trauma (EFAST). J Trauma 2004;57:288-95.

30. Blaivas M, Lyon M, Duggal S. A prospective comparison of supine chest radiography and bedside ultrasound for the diagnosis of traumatic pneumothorax. Acad Emerg Med 2005;12:844-9. 
31. Soldati G, Testa A, Sher S, et al. Occult traumatic pneumothorax: Diagnostic accuracy of lung ultrasonography in the emergency department. Chest 2008;133:204-11.

32. Alrajhi K, Woo MY, Vaillancourt C. Test characteristics of ultrasonography for the detection of pneumothorax: A systematic review and meta-analysis. Chest 2012;141:703-8.

33. Malloy PC, Richard HM. Thoracic angiography and intervention in trauma. Radiol Clin North Am 2006;44:239-49.

34. Chung JH, Carr RB, Stern EJ. Extrapleural hematomas: Imaging appearance, classification, and clinical significance. J Thorac Imaging 2011;26:218-23.

35. Liman ST, Kuzucu A, Tastepe AI, et al. Chest injury due to blunt trauma. Eur J Cardiothorac Surg 2003;23:374-8.

36. Galvez C, Arenas-Jimenez J, Del Campo J, et al. An extended FAST examination that diagnoses the presence of rib fracture. Asvide 2020;7:036. Available online: http://www.asvide.com/watch/33075

37. Cho SH, Sung YM, Kim MS. Missed rib fractures on evaluation of initial chest CT for trauma patients: Pattern analysis and diagnostic value of coronal multiplanar reconstruction images with multidetector row CT. Br J Radiol 2012;85:845-50.

38. Urbaneja A, De Verbizier J, Formery AS, et al. Automatic rib cage unfolding with CT cylindrical projection reformat in polytraumatized patients for rib fracture detection and characterization: Feasibility and clinical application. Eur J Radiol 2019;110:121-7.

39. Pulley BR, Taylor BC, Fowler TT, et al. Utility of threedimensional computed tomography for the surgical management of rib fractures. J Trauma Acute Care Surg 2015;78:530-4.

40. Chen YY, Lin KH, Huang HK, et al. Preoperative threedimensional printing for surgical stabilization of Rib fractures. J Med Sci 2018;38:46-8.

41. Talbot BS, Gange CP, Chaturvedi A, et al. Traumatic rib injury: Patterns, imaging pitfalls, complications, and treatment. Radiographics 2017;37:628-51.

42. Sammy IA, Chatha H, Lecky F, et al. Are first rib fractures a marker for other life-threatening injuries in patients with major trauma? A cohort study of patients on the UK Trauma Audit and Research Network database. Emerg Med J 2017;34:205-11.

43. Park S. Clinical analysis for the correlation of intraabdominal organ injury in the patients with RIB fracture. Korean J Thorac Cardiovasc Surg 2012;45:246-50.
44. De Waele JJ, Calle PA, Blondeel L, et al. Blunt cardiac injury in patients with isolated sternal fractures: The importance of fracture grading. Eur J Trauma 2002;28:178-82.

45. Knobloch K, Wagner S, Haasper C, et al. Sternal Fractures Occur Most Often in Old Cars to Seat-Belted Drivers Without Any Airbag Often With Concomitant Spinal Injuries: Clinical Findings and Technical Collision Variables Among 42,055 Crash Victims. Ann Thorac Surg 2006;82:444-50.

46. Scheyerer MJ, Zimmermann SM, Bouaicha S, et al. Location of sternal fractures as a possible marker for associated injuries. Emerg Med Int 2013;2013:407589.

47. Ball CG, Kirkpatrick AW, Laupland KB, et al. Incidence, risk factors, and outcomes for occult pneumothoraces in victims of major trauma. J Trauma 2005;59:917-24; discussion 924-5.

48. Wagner RB, Crawford WO, Schimpf PP. Classification of parenchymal injuries of the lung. Radiology 1988;167:77-82.

49. Wintermark M, Schnyder P. The Macklin effect: A frequent etiology for pneumomediastinum in severe blunt chest trauma. Chest 2001;120:543-7.

50. Elie M. Blunt cardiac injury. Mt Sinai J Med 2006;73:542-52.

51. Shah R, Sabanathan S, Mearns AJ, et al. Traumatic rupture of diaphragm. Ann Thorac Surg 1995;60:1444-9.

52. Andrus C, Morton J. Rupture of the Diaphragm after Blunt Trauma. Am J Surg 1970;119:686-93.

53. Hanna WC, Ferri LE, Fata P, et al. The Current Status of Traumatic Diaphragmatic Injury: Lessons Learned From 105 Patients Over 13 Years. Ann Thorac Surg 2008;85:1044-8.

54. Kearney PA, Rouhana SW, Burney RE. Blunt rupture of the diaphragm: Mechanism, diagnosis, and treatment. Ann Emerg Med 1989;18:1326-30.

55. Grimes OF. Traumatic injuries of the diaphragm. Diaphragmatic hernia. Am J Surg 1974;128:175-81.

56. Carter B, Giuseffi J, Felson B. Traumatic diaphragmatic hernia. Am J Roentgenol Radium Ther 1951;65:56-72.

57. Murray JG, Caoili E, Gruden JF, et al. Acute rupture of the diaphragm due to blunt trauma: Diagnostic sensitivity and specificity of CT. Am J Roentgenol 1996;166:1035-9.

58. Israel R, Mayberry J, Primack S. Diaphragmatic rupture. AJR AM J Roentgenol 1996;167:1201-3.

59. Steenburg SD, Ravenel JG, Ikonomidis JS, et al. Acute traumatic aortic injury: Imaging evaluation and management. Radiology 2008;248:748-62. 
60. Malhotra AK, Fabian TC, Croce MA, et al. Minimal aortic injury: a lesion associated with advancing diagnostic techniques. J Trauma 2001;51:1042-8.

61. Lee WA, Matsumura JS, Mitchell RS, et al. Endovascular repair of traumatic thoracic aortic injury: Clinical practice guidelines of the Society for Vascular Surgery. J Vasc Surg 2011;53:187-92.

62. Fox N, Schwartz D, Salazar JH, et al. Evaluation and management of blunt traumatic aortic injury. J Trauma Acute Care Surg 2015;78:136-46.

63. Bergeron E, Clement J, Lavoie A, et al. A simple fall in the elderly: not so simple. J Trauma 2006;60:268-73.

64. Barnea Y, Kashtan H, Skornick Y, et al. Isolated rib fractures in elderly patients: Mortality and morbidity. Can J Surg 2002;45:43-6.

65. Yousefifard M, Baikpour M, Ghelichkhani P, et al.

doi: $10.21037 /$ jovs.2019.11.08

Cite this article as: Galvez C, Arenas-Jimenez J, Del Campo J, Maroto S, Sirera M, Lirio F. Diagnostic imaging pathways in the setting of acute chest wall trauma. J Vis Surg 2020;6:21.
Comparison of Ultrasonography and Radiography in Detection of Thoracic Bone Fractures; a Systematic Review and Meta-Analysis. Emerg (Tehran) 2016;4:5564.

66. Miller LA. Chest wall, lung, and pleural space trauma. Radiol Clin North Am 2006;44:213-24.

67. von Garrel T, Ince A, Junge A, et al. The sternal fracture: Radiographic analysis of 200 fractures with special reference to concomitant injuries. J Trauma 2004;57:837-44.

68. Athanassiadi K, Gerazounis M, Moustardas M, et al. Sternal fractures: Retrospective analysis of 100 cases. World J Surg 2002;26:1243-6.

69. Martinez Serna I, Mariscal de Alba M, Hermoso Alarza R, et al. Hernia pulmonar intercostal espontánea secundaria a cuadro de tos. Rev Patol Respir 2012;15:89-91. 